\title{
MECHANICAL AND CHEMICAL RESISTANCE OF THERMOCHROMIC PACKAGING PRINTS
}

\author{
Sonja Jamnicki Hanzer (D), Rahela Kulčar (D), Marina Vukoje (D), Petra Širol \\ University of Zagreb, Faculty of Graphic Arts, Zagreb, Croatia
}

\begin{abstract}
Thermochromic inks are temperature-sensitive materials that change colour due to a temperature change. These inks are mostly printed on smart packaging applications where they are used in a form of temperature indicators. The colorants in these inks are microencapsulated which makes the prints obtained with these inks more sensitive to abrasion in comparison to the prints obtained with conventional inks. Thermochromic prints are also very sensitive to adverse environmental conditions, such as exposure to UV light, heat and certain chemicals and solvents.

Abrasion and chemical resistance of thermochromic prints obtained on metallized label papers are discussed in this paper. For that purpose, two thermochromic UV screen inks were printed on two types of metalized papers that are commonly used as food packaging labels. The prints thus obtained were then subjected to a rub test in accordance with standard method BS 3110. Rub test was performed using Hanatek RT4 Rub and Abrasion Tester. The degree of rubbing was assessed by visual inspection and by detection of the colorimetric changes on the prints after their exposure to rubbing. Assessment of prints' resistance to various liquid agents (water, ethanol and citric acid) was done in accordance to standard method ISO 2836. Evaluation of chemical degradation on prints was done by the spectrophotometric measurements.

The results of conducted research showed good rub resistance of these inks, as no rubbing was detected, but poor resistance to all liquid agents they were exposed to. Exposure to ethanol, particularly, caused severe damage to the prints. The bleeding of the colorants from the prints was also detected. However, even though the prints were not able to completely withstand exposure to specific liquid agents which was demonstrated by their optical deterioration, the thermochromic effect was still present in them after resistance tests were conducted.
\end{abstract}

Key words: thermochromic inks, metallized label paper, rub resistance, chemical resistance

\section{INTRODUCTION}

Thermochromic (TC) inks are temperature sensitive inks that exhibit colour changes in response to temperature fluctuations. There are two primary types of TC inks: liquid crystals and leuco dyes. Leuco dye-based inks are being used more often, especially in smart packaging applications. TC inks can go from colourful to colourless, colourless to colourful, or can change from one colour to another. Moreover, the change of colour may be irreversible or reversible. In case of irreversible inks, a colour change is permanent, while reversible inks exhibit a temporary colour change i.e. the original colour is restored upon cooling. Each thermochromic colorant has a fixed temperature range over which its colour change takes place. This temperature range is called the activation temperature $\left(T_{A}\right)$ or activation point (Bäckman, 2017; Kulčar et al, 2010; Lam Po Tang and Stylios, 2006; Seeboth and Lotzsch, 2013).

TC inks based on leuco dyes generally consist of an encapsulated three-part system which includes a dye that changes colour, a compound that acts as a colour developer and a solvent. At temperatures below the activation point, the solvent is in solid state enabling the dye and colour developer to form a colour, resulting in a full colour effect. When the temperature reaches the activation point, the solvent becomes liquid, keeping colour developer and the leuco dye apart (WRAP, 2013).

Depending on the application, TC inks can be applied with many printing processes, including offset lithography, flexography, gravure, and screen printing (Homola, 2008). The formulation of TC inks includes a mixture of TC microcapsules dispersed in ink's vehicles. The sizes of microcapsules used in printing inks are in the range of 3 to $5 \mu \mathrm{m}$ which makes them at least ten times larger than the average size of the colorants used in the formulation of conventional printing inks. The main disadvantage of microencapsulated TC systems is their limited lightfastness and resistance to different atmospheric conditions (Seeboth and Lotzsch, 2008). Moreover, the microencapsulation of TC colorants makes TC inks significantly more susceptible to abrasion than conventional printing inks.

In recent years, applications for TC inks have expanded. They have found their main application in the food industry as indicators printed on smart packaging, where are used to enhance labels, give warnings 
or the advice of correct consumption temperature (Đurđević et al, 2015). They can also be found in security printing, where are used on checks, tickets, medication recipes, etc. Recently, such inks are gaining their roles in commercial purposes - decorations, design solutions, promotional materials etc.

During the shipping or handling process, printed products are often exposed to a degree of abrasion to its surface. This abrasion can result in a significant degradation in the appearance of the prints i.e. a print defect could appear in form of scuffed, rubbed off or scratched surface. Rub resistance, in particular, describes the ability of printed product to withstand marking, scuffing or smudging during handling in conversion, packaging, distribution and use (Bozhkova et al, 2017). A good rub resistance is expected for prints applied on labels and packaging, but also for prints applied on the covers of books, magazines, notebooks or folders. The main factors influencing on ink rub resistance are the basic properties of paper (smoothness, absorption ability, etc.), the composition of the ink, printing conditions and ink drying properties (Zhou et al, 2011). Alongside to abrasion that could negatively affect packaging prints also certain chemicals can cause print's alterations: either by direct degradation of the print in contact with the product or by the migration of an ingredient into the ink. A print is considered to be resistant to a chemical substance when no alteration occurs when it is brought into contact with it, i.e. when no change in colour, no leaching, no reduction in the abrasion or scratch resistance of printed film is observed (Brancher, 2020).

This research aimed to analyze mechanical and chemical resistance of UV cured thermochromic inks applied on metallized label papers. For that reason, the prints were subjected to a standard rub test and they were also treated with three liquid agents to prove the prints' resistance to liquids and chemicals. The degree of rubbing was assessed by visual inspection and by detection of the colorimetric changes on the prints after their exposure to rubbing. Chemical resistance of prints was observed based on optical deterioration of prints after treatments with liquid agents compared against untreated prints.

\section{MATERIALS AND METHODS}

\subsection{Printing substrates}

As printing substrates two metallized label papers were selected, one of which had embossed metallized surface (Alukett Spezial Fashion by B\&B), and another which had more uniform and radiant surface (Alukett Spezial by B\&B). Both metallized papers had a functional coating on the reverse side as they were designed to be used as beer labels. The characteristics of metallized label papers given by the producer are presented in Table 1.

Table 1: Characteristics of metallized label papers

\begin{tabular}{|c|c|c|c|c|c|}
\hline Paper grade & \multicolumn{5}{|c|}{ Property } \\
\hline & $\begin{array}{c}\text { Basis weight } \\
\mathrm{g} / \mathrm{m}^{2} \\
(\text { ISO 536) }\end{array}$ & $\begin{array}{c}\text { Caliper } \\
\mu \mathrm{m} \\
\text { (ISO 534) }\end{array}$ & $\begin{array}{c}\text { Gloss Novogloss } \\
\text { (coated side) } \\
\%\end{array}$ & $\begin{array}{c}\text { Smoothness Bekk } \\
\text { (reverse side) } \\
\text { Bekk Sec. } \\
(\text { ISO 5627) }\end{array}$ & $\begin{array}{c}\text { Cobb 60" } \\
\text { (reverse side) } \\
\mathrm{g} / \mathrm{m}^{2} \\
(\text { ISO 535) }\end{array}$ \\
\hline Alukett Spezial & 71 & 64 & 35 & 250 & 17 \\
\hline $\begin{array}{c}\text { Alukett Spezial } \\
\text { Fashion }\end{array}$ & 71 & 65 & - & 150 & 17 \\
\hline
\end{tabular}

\subsection{Printing inks}

Two thermochromic UV screen inks manufactured by commercial producer were chosen for printing on metallized substrates. These inks were coloured below a specific temperature and changed to another lighter colour as they were heated. One ink was coloured in orange below its activation temperature $\left(\mathrm{T}_{\mathrm{A}}=12^{\circ} \mathrm{C}\right)$ and changed to yellow above it (hereinafter $\left.\mathrm{OY}_{12}\right)$. Another ink was coloured in purple below its activation temperature $\left(T_{A}=31^{\circ} \mathrm{C}\right)$ and changed to pink above it (hereinafter $\mathrm{PP}_{31}$ ). Both inks were type of reversible inks i.e., the original colour was restored upon cooling (Figure 1). These inks consisted of two types of colorants: thermochromic leuco dyes and conventional pigments (Homola, 2008). We can assume that orange $\left(\mathrm{OY}_{12}\right.$ ) ink was made by addition of red leuco dyes to conventional yellow pigments, while purple $\left(\mathrm{PP}_{31}\right)$ ink was made by combination of conventional pink pigments with blue leuco dyes. 


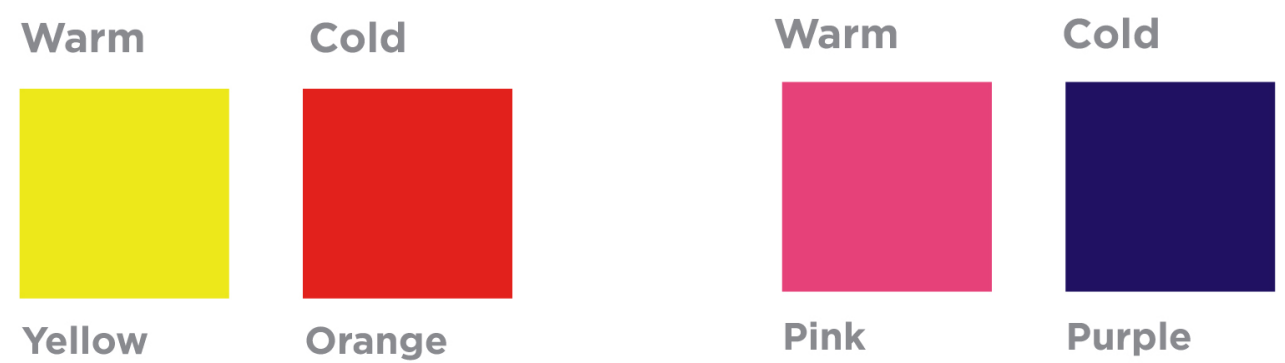

Figure 1: The colour of used thermochromic inks in their warm (above $T_{A}$ ) and cold state (below $T_{A}$ )

Printing was conducted in laboratory conditions by semi-automatic screen printing device Siebdruckgeräte von Holzschuher KG., Wuppertal, using a mesh of 62-64 lin/cm. The prints were printed in full tone. After printing, they were cured in a Technigraf Aktiprint L 10-1 UV dryer (30 W/cm). The characteristics of inks given by the producer are presented in Table 2.

Table 2: Characteristics of thermochromic UV screen inks

\begin{tabular}{|c|c|}
\hline UV thermochromic ink & D12-Flatbed \\
\hline Viscosity at $25^{\circ} \mathrm{C}$ & $65-110$ poise \\
\hline Density (Approx.) & $8.0 \mathrm{lb} . /$ gal \\
\hline Appearance & Viscous Liquid \\
\hline Percent Solids (Approx.) & $99 \%$ \\
\hline Percent Volatiles (Approx.) & $<1.5 \%$ \\
\hline
\end{tabular}

\subsection{Rub test trials}

A Hanatek RT4 Rub and Abrasion Tester was used for testing the rub resistance of the printed samples. The testing was done in accordance to British Standard BS 3110:1959 (British Standards Institution, 1959). The rub resistance was determined on a dry print in terms of removal of a layer of ink due to friction, created by rubbing the examined print against white uncoated paper $\left(80 \mathrm{~g} / \mathrm{m}^{2}\right)$. The white uncoated paper was used to clearly see the ink transference. Powered by an electric motor, the disc with the facedown attached printed sample and the disc with the white paper substrate rotated at an identical speed of $1 \mathrm{rev} / \mathrm{sec}$ under the constant rubbing pressure. The pressure between discs was regulated by different weights placed on the upper disk. Tests were performed at two varying pressures: 3.6 and 6.9 $\mathrm{kPa}$. A number of rubs (revolutions) was set to 50 for each tested sample. For each sample (ink/substrate combination), three tests were performed. The degree of surface rub was assessed by visual inspection (the degree of dry ink transfer onto a white uncoated paper) and by detection of the colorimetric changes on the prints.

\subsection{Assessment of prints' resistance to various chemical agents}

Assessment of prints' resistance to various chemical agents (water, ethanol and citric acid) was done in accordance to standard method ISO 2836:2004. International Standard ISO 2836:2004 in the field of printing industry defines methods of assessing the resistance of prints to liquid and solid agents, solvents, varnishes and acids (International Organization for Standardization, 2004). Water, ethanol and citric acid were chosen as test agents because laboratory prints were made on metallized beverage labels, so the selected agents simulated water, alcohol and juice of citrus fruits.

For assessment of prints' resistance to water, four strips of filter paper were immersed into distilled water and then drained until no water drops were dripping off filter paper. Two saturated strips of filter paper were then placed on the lower glass plate; the printed test piece was placed on the top of them and was covered with other two strips of saturated filter papers. The top glass plate was then placed covering filter papers and load of $1 \mathrm{~kg}$ mass on top of that all. The package was left for 24 hours at ambient temperature. After the treatment, the laboratory prints were dried in an oven for 30 minutes at a temperature of $40{ }^{\circ} \mathrm{C}$. The assessment was made of any changes in the print and in the receptor (filter paper) surface which has been in the contact with print. 
The method of testing resistance of prints to ethanol was performed in a test tube, which was half-filled with denatured ethanol (96\%). The printed test piece was submerged in the solvent and was left in it for 5 minutes. The test temperature was $23^{\circ} \mathrm{C}$. After exposure time was over, the laboratory prints were dried in an oven for 10 minutes at a temperature of $40{ }^{\circ} \mathrm{C}$. The colour change of the solvent and discoloration and any change of the test piece (print) were noted and reported.

For assessment of prints' resistance to citric acid, two strips of filter paper were immersed in the $5 \%$ citric acid and then drained until there were no solution drops dripping off filter paper. One saturated strip of filter paper was then placed on the lower glass plate with the laboratory print placed on it. That same print was then covered with another saturated filter paper and the second glass was placed on top of everything. The whole was placed in a moisture-tight wrapper. Also, $1 \mathrm{~kg}$ of load was placed on top of it all to provide pressure. The exposure time was set to 1 hour, at a temperature of $23^{\circ} \mathrm{C}$. After exposure was over, the print was rinsed in deionized water and was left to dry in the oven at $50{ }^{\circ} \mathrm{C}$ for 30 minutes. An assessment was made of any change to the print and any bleeding of the colour onto the filter paper. Summarized details of test conditions for conducted chemical resistance test methods are presented in Table 3.

Table 3: Test conditions for used liquid agents

\begin{tabular}{|c|c|c|c|c|}
\hline Test agent & Receptor surface & Temperature ${ }^{\circ} \mathrm{C}$ & Test duration & Contact condition \\
\hline Water (distilled) & filter paper & $23 \pm 2$ & $24 \mathrm{~h}$ & $1 \mathrm{~kg} \mathrm{on} 54 \mathrm{~cm}^{2}$ \\
\hline Ethanol $(\mathrm{v} / \mathrm{v}=96 \%)$ & test tube & $23 \pm 2$ & $5 \mathrm{~min}$ & liquid \\
\hline Citric acid $(\mathrm{w} / \mathrm{v}=5 \%)$ & filter paper & $23 \pm 2$ & $1 \mathrm{~h}$ & $1 \mathrm{~kg}$ on $54 \mathrm{~cm}^{2}$ \\
\hline
\end{tabular}

\subsection{Spectrophotometric measurements}

Evaluation of mechanical and chemical degradation on prints was done by the spectrophotometric measurements. Spectrophotometric measurements were conducted on laboratory prints before and after their exposure to mechanical and chemical treatments. Temperature-dependent spectral reflectance of the samples was measured (spectral region 430-700 nm, $1 \mathrm{~nm}$ step) by fiber-based USB 2000 spectrometer (Ocean Optics, USA) using $30 \mathrm{~mm}$ wide integrating sphere (ISP-30-6-R) with $\left(8^{\circ}:\right.$ di) measuring geometry and $6 \mathrm{~mm}$ sampling port diameter. OceanView software by Ocean Optics was used to calculate the CIELAB $L^{*}, a^{*}, b^{*}$ values taking into account the D50 illuminant and $2^{\circ}$ standard observer. The samples were heated on the surface of a water block (EK Water Blocks; EKWB d.o.o., Slovenia).

For evaluation of mechanical and chemical degradation, the colour difference between the prints before and after conducted treatments was calculated using the formula CIEDE2000 (CIE, 2004). Each printed sample was measured 3 times at 3 different positions on the print area.

For evaluation of prints' rub resistance properties, spectroscopic measurements were done at constant temperature of $20^{\circ} \mathrm{C}$ for both inks, while in case of evaluation of prints' optical deterioration caused by liquid agents, spectroscopic measurements were done at two fixed temperatures for each TC print: one below its $T_{A}$, and another above its $T_{A}$. For that reason, prints made with $O Y_{12}$ ink were measured at $8^{\circ} \mathrm{C}$ and $20^{\circ} \mathrm{C}$, while prints made with $\mathrm{PP}_{31}$ ink were measured at $20^{\circ} \mathrm{C}$ and $40^{\circ} \mathrm{C}$, respectively.

Interpretation of measured colour-difference parameter $\triangle \mathrm{E}$ from the CIEDE2000 formula was done in relation to subjective visual perception. If the calculated CIEDE2000 results are below 1 , then the average eye of the observer cannot perceive the difference between two colours. A very small difference between colours can be perceived when the results are between 1 and 2 , but it is tolerated, that is, the colour difference up to 2 is acceptable (Rudolf et al, 2020).

\section{RESULTS AND DISCUSSION}

\subsection{Results of rub resistance measurements}

After series of rub tests performed on TC prints, samples of white paper were then visually inspected to determine if the rub resistances of prints were satisfactory. The results showed that all printed samples had high rub resistance, at all tested conditions, as no transfer of dry ink onto the white uncoated paper was observed. Alongside to that, the colour difference CIEDE2000 between printed samples before and after conducted rub tests was determined and the results are presented in Figure 2 and Figure 3. 


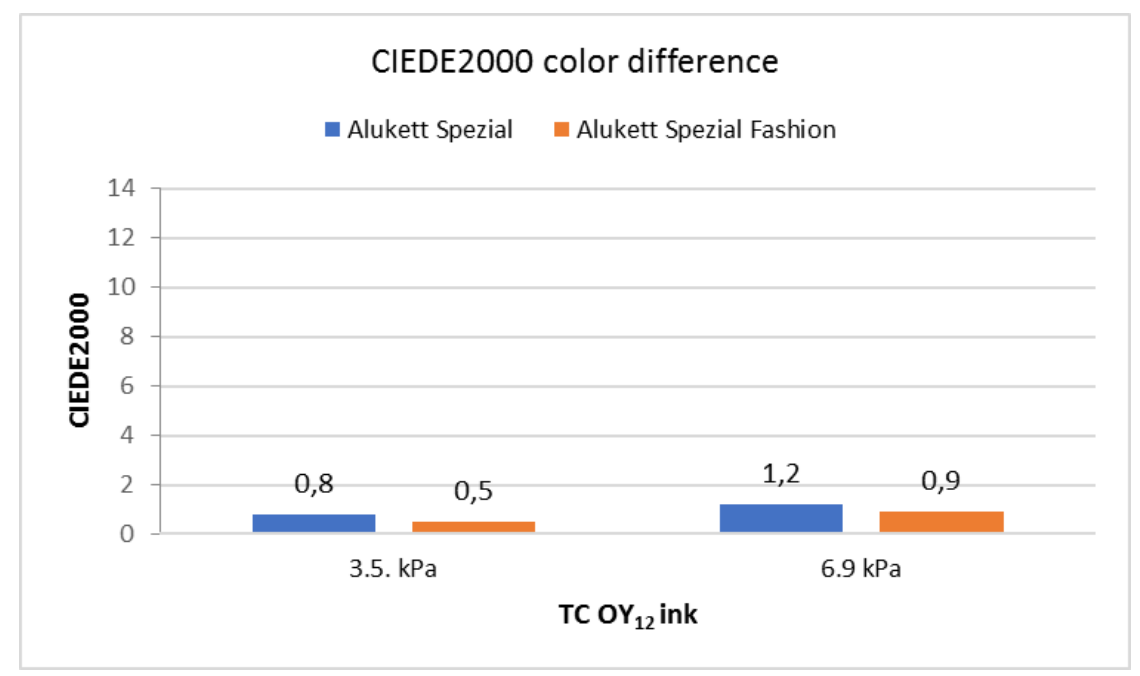

Figure 2: Colour difference measured on the $\mathrm{TCOY}_{12}$ prints after their exposure to rubbing

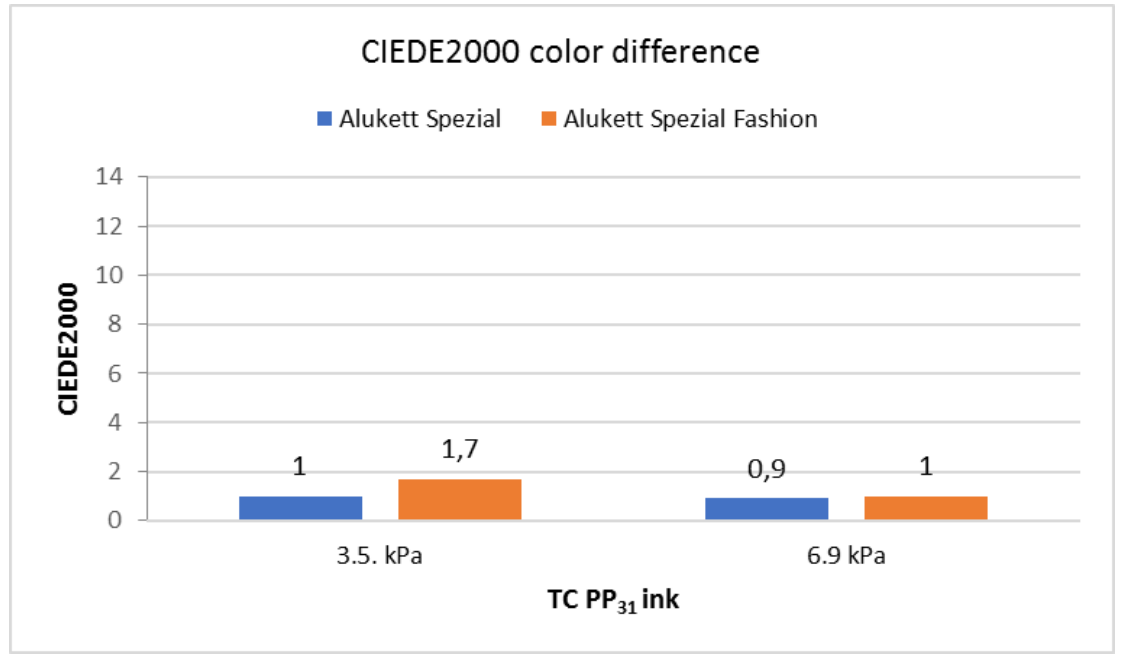

Figure 3: Colour difference measured on the TC $P P_{31}$ prints after their exposure to rubbing

The results show that both tested inks applied on both substrates, under all testing conditions, showed minimal optical deterioration on their prints, as all measured CIEDE2000 results were below 2 (which is considered as an acceptable colour difference). These results correspond well to the results of previously conducted visual assessment. However, if we further compare the results obtained between two thermochromic inks, the $\mathrm{OY}_{12}$ ink showed slightly better results than $\mathrm{PP}_{31}$ ink, especially when printed on an embossed metallized substrate (Alukett Spezial Fashion), where measured colour difference was under 1 , which means that the average eye of the observer couldn't perceive the difference between two colours. The results of rub tests for both inks applied on both substrates are satisfactory.

\subsection{Results of prints' chemical resistance}

Assessment of the prints' resistance to chemical agents was done based on any colour changes in the prints and in the receptor (filter paper or testing solvent). After treatment with water, for both tested metallized label papers, a moderate bleeding was noticed in case of $\mathrm{PP}_{31}$ prints (filter papers that were in direct contact with prints were lightly coloured in pink at their contact surface), but in case of OY 12 prints no bleeding was visually inspected. In case of prints' exposition to ethanol, the remaining solvent in the test tube was highly coloured in yellow and in pink as severe bleeding from $\mathrm{OY}_{12}$ and $\mathrm{PP}_{31}$ prints from both label papers was noticed. Moreover, exposure to ethanol caused severe damage to the prints which can be seen in Figure 4. Discoloration of the print surface was noticed, and some areas of the prints were completely peeled off the metallized label paper surfaces. This would mean that ethanol destroys the attractive forces between the TC ink and paper, affecting the ink adhesion onto the paper. 

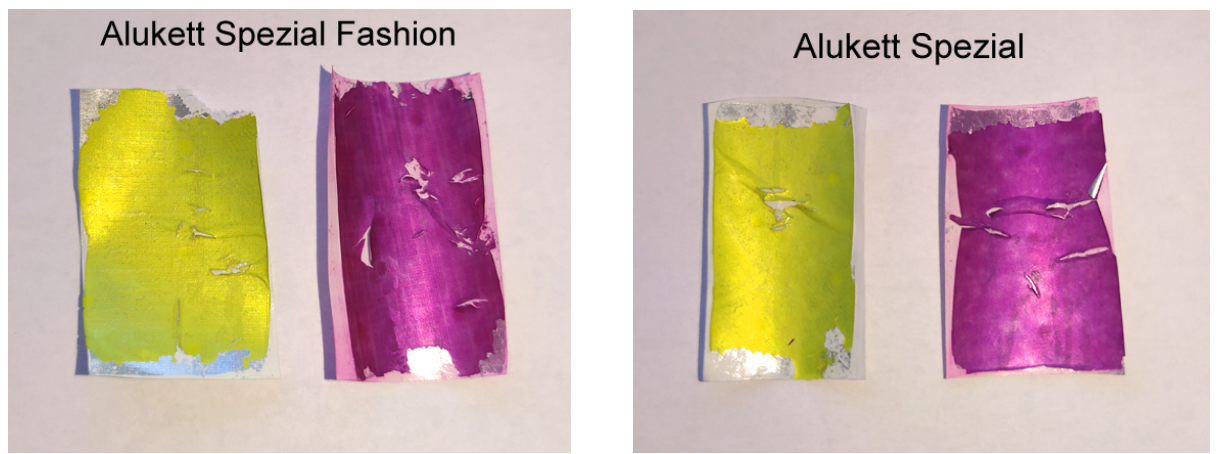

Figure 4: Appearance of the prints after treatment with ethanol

In addition, after treatment with citric acid, for both tested metallized label papers, quite high bleeding of colorants into the filter papers was detected in case of $\mathrm{PP}_{31}$ inks, while the only slight indication of bleeding was detected from $\mathrm{OY}_{12}$ ink printed on Alukett Spezial label paper, and in case of the same ink printed on embossed Alukett Spezial Fashion label paper, no bleeding was detected.

Figures 5-8 present the CIEDE2000 colour difference of the prints measured at temperatures below and above TC inks' $T_{A}$.

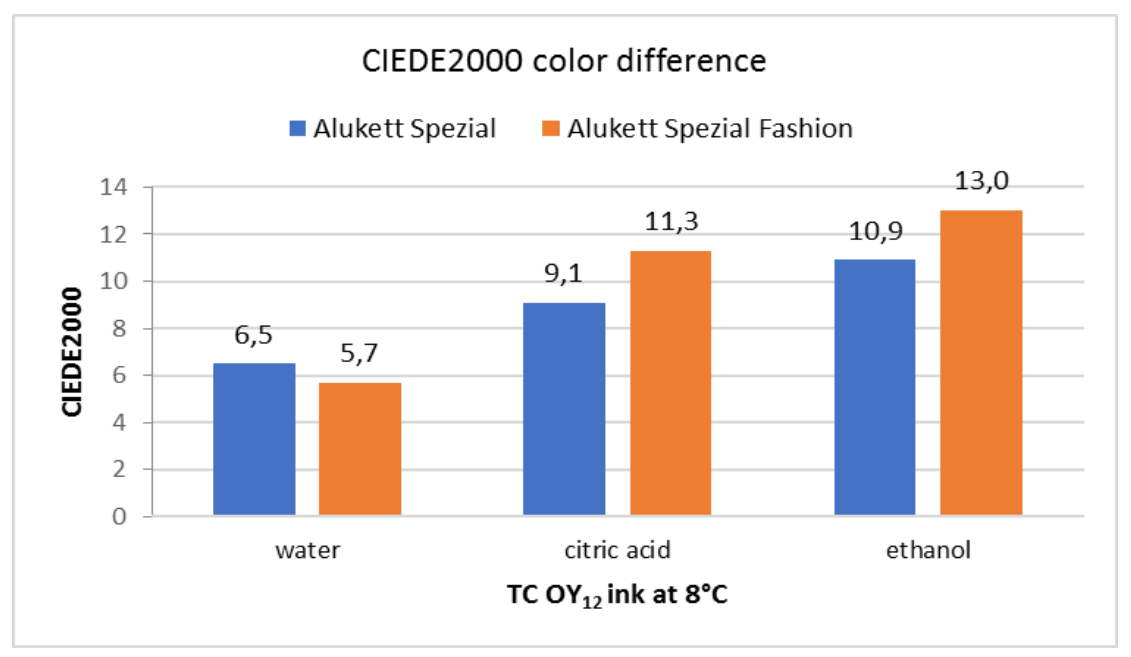

Figure 5: CIEDE2000 colour differences measured on OY 12 TC prints below inks' $T_{A}$ after treatments with chemical agents

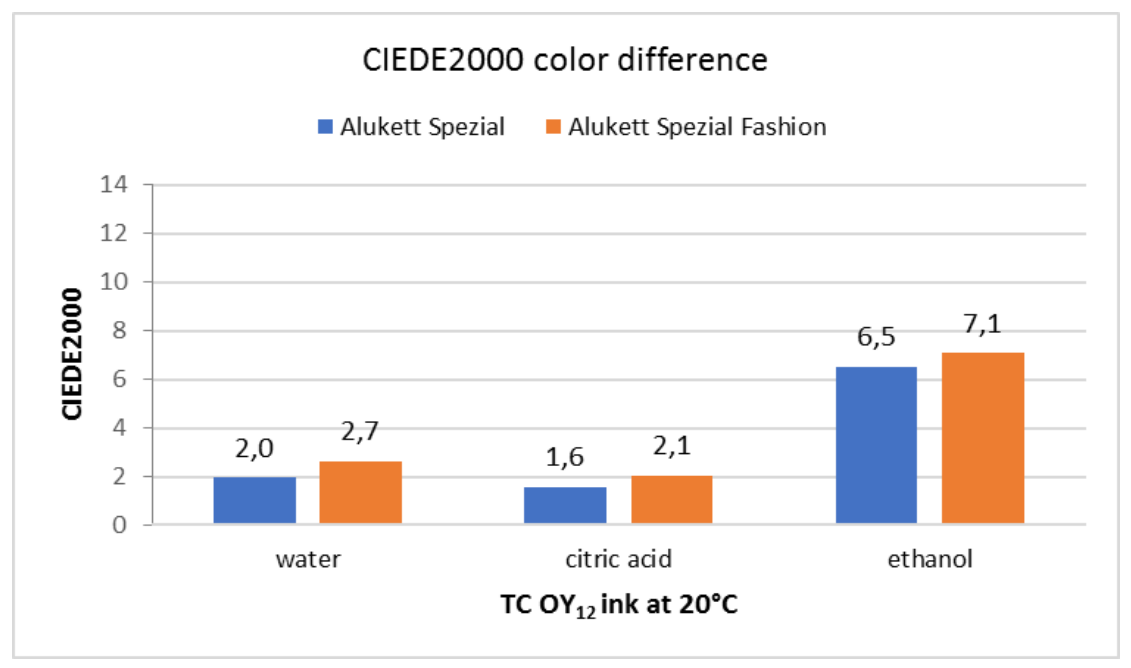

Figure 6: CIEDE2000 colour differences measured on OY 12 TC prints above inks' $T_{A}$ after treatments with chemical agents 


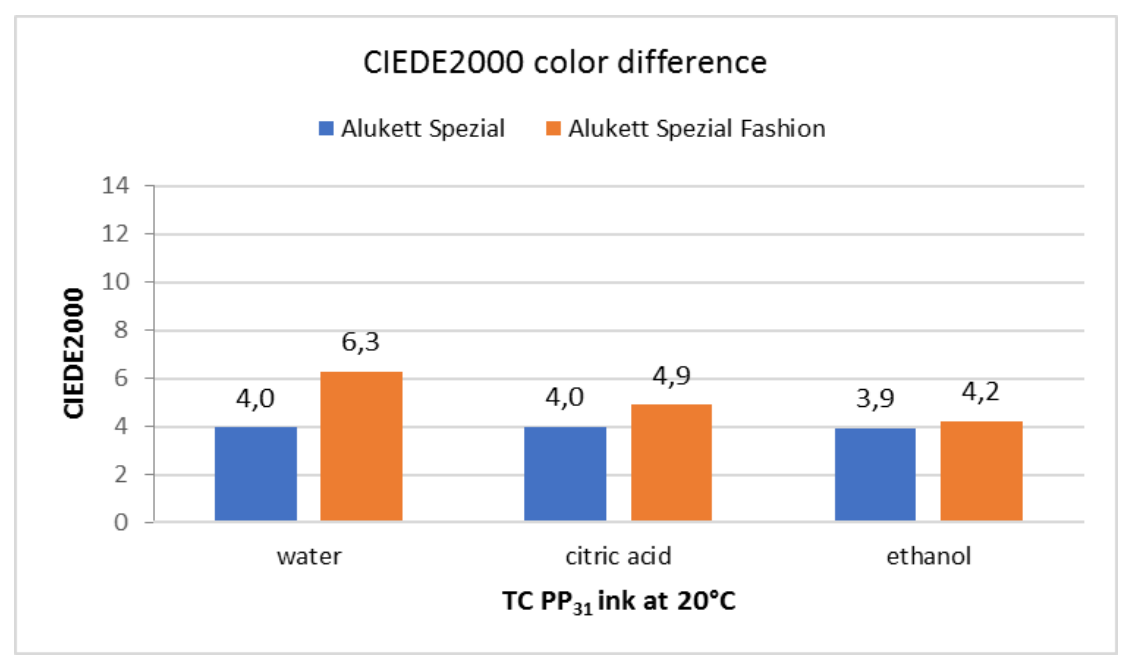

Figure 7: CIEDE2000 colour differences measured on PP 31 TC prints below inks' $T_{A}$ after treatments with chemical agents

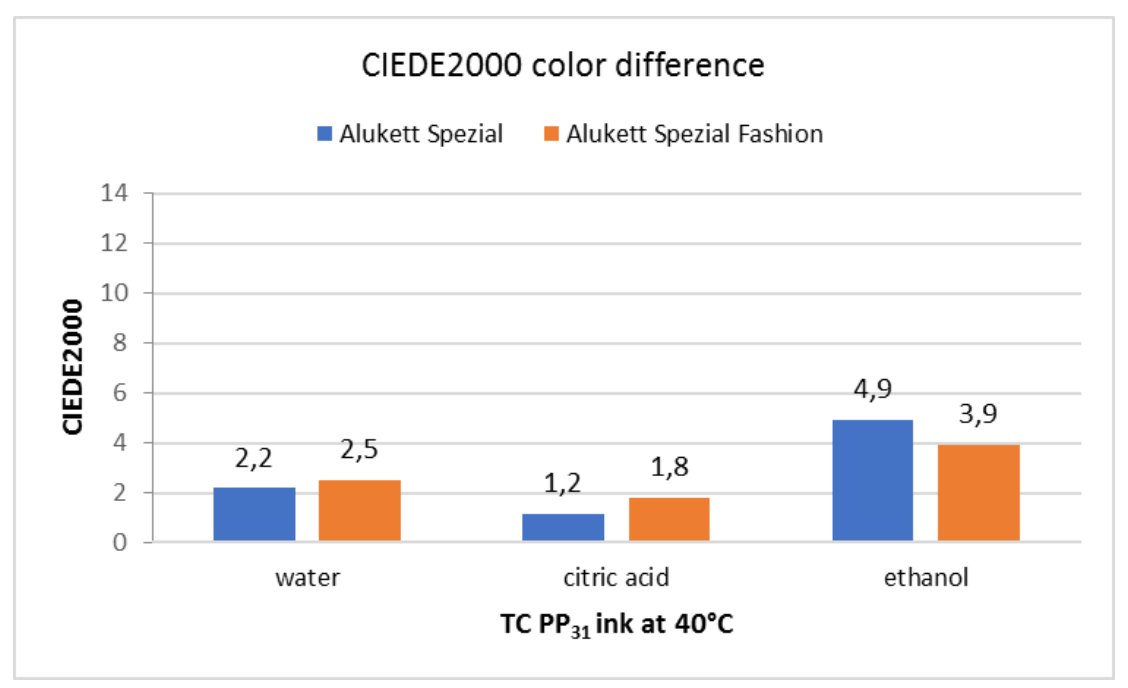

Figure 8: CIEDE2000 colour differences measured on $P P_{31} T C$ prints above inks' $T_{A}$ after treatments with chemical agents

If we compare CIEDE2000 colour differences measured on TC prints, for both inks, at all testing conditions, we can see the greatest effect of all liquid agents on the prints when thermochromic microcapsules are active, at $8{ }^{\circ} \mathrm{C}$ for $\mathrm{OY}_{12}$ ink and at $20^{\circ} \mathrm{C}$ for $\mathrm{PP}_{31}$ ink. It is also evident from the results that the prints made with $\mathrm{OY}_{12}$ ink were affected more by selected liquid agents that those printed with $\mathrm{PP}_{31}$ ink. One possible explanation of differences in results obtained between $\mathrm{OY}_{12}$ and $\mathrm{PP}_{31}$ prints can be the different chemical structure of the TC ink used, i.e. different composition of the TC ink binder formulation. Depending on the structure of the binder and colorants (presence of polar or non-polar groups within the structure), different reactions (dispersion, polar or hydrogen) will occur between the prints and the liquid agents used i.e. one material will dissolve in another, if they have similar behaviour or if they react in a similar way (Rožić et al, 2017)). In this case, the liquid agents used did not affect equally the $\mathrm{OY}_{12}$ and $\mathrm{PP}_{31}$ prints, therefore a different chemical structure of the used TC inks can be assumed.

Results further show a pattern of prints coloration change due to different polarity of the solvents. Polarity increases in a row: ethanol < citric acid < water. Ethanol as a strong solvent, by the action of its polar and hydrogen interactions with the print, creates greater differences in the colour of the print in contrast to the other two liquid agents used.

Moreover, there is as well, the influence of paper topography evident. If we compare the obtained results from the aspect of the printing substrates, inks printed on the embossed metallized substrate (Alukett Spezial Fashion), in most cases, were slightly less resistant to liquid chemical agents. Or, it is maybe 
possible that on rougher surface, where deposited ink adheres to the irregularities of the embossed surface, the change in colour caused by treatment with the liquid agents, becomes more prominent than on smoother surface where ink is deposited in more uniform layer.

Also, it should be noted that, even though the prints were not able to completely withstand exposure to specific liquid agents which was demonstrated by their optical deterioration, the thermochromic effect was still present in them after resistance tests were conducted.

Figures 9-11 show reflectance spectra for tested TC prints on both substrates before and after treatment with each specific liquid.
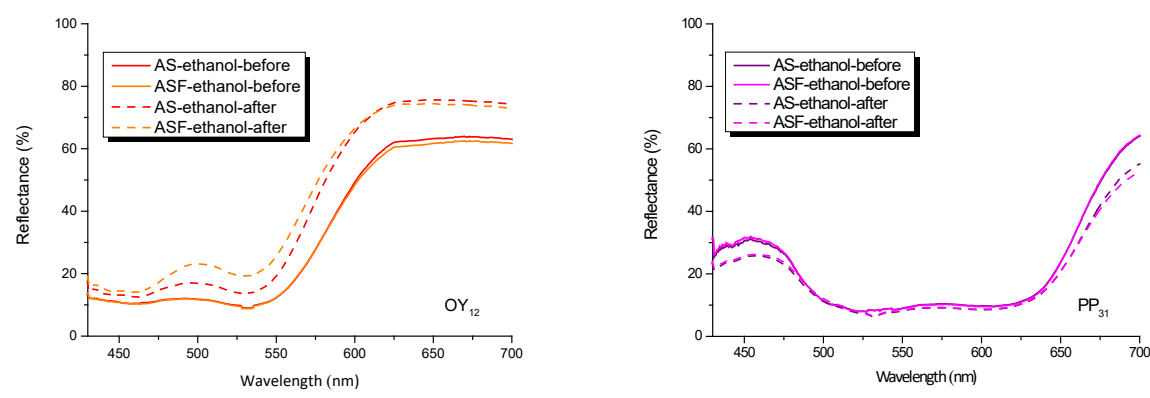

Figure 9: Spectral reflectance curves for the $\mathrm{OY}_{12}$ and $P P_{31}$ samples on two papers (AS - Alukett Spezial, ASF - Alukett Spezial Fashion), before and after treatment with ethanol
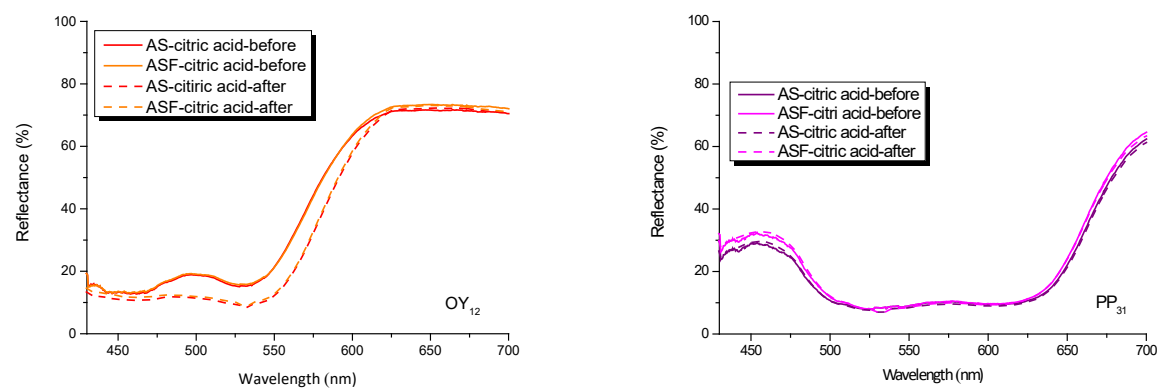

Figure 10: Spectral reflectance curves for the $O Y_{12}$ and $P P_{31}$ samples on two papers (AS - Alukett Spezial, ASF - Alukett Spezial Fashion), before and after treatment with citric acid
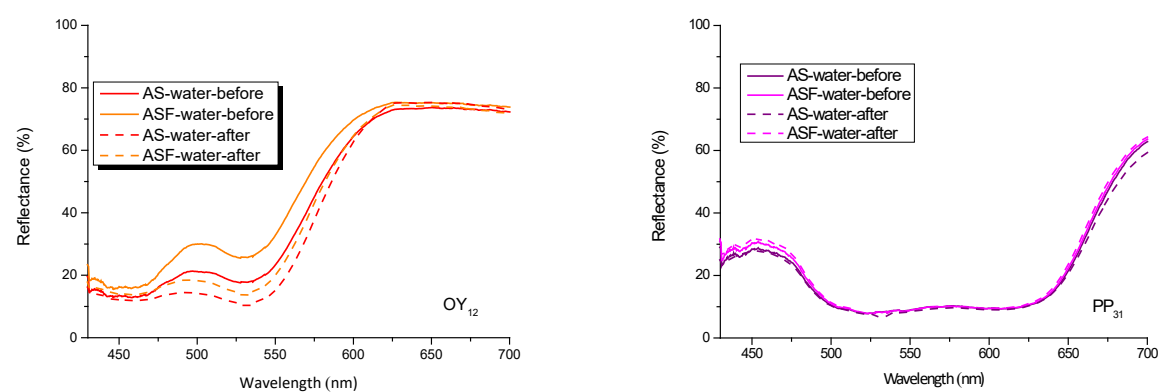

Figure 11: Spectral reflectance curves for the $O Y_{12}$ and $P P_{31}$ samples on two papers (AS - Alukett Spezial, ASF - Alukett Spezial Fashion), before and after treatment with water

At temperatures at which TC microcapsules are active $\left(\mathrm{OY}_{12}\right.$ at $8^{\circ} \mathrm{C}$ and $\mathrm{PP}_{31}$ at $20^{\circ} \mathrm{C}$ ), spectral reflectance curves in the range of 430 to $700 \mathrm{~nm}$ were read. Larger deviations are evident from the curves on the $\mathrm{OY}_{12}$ sample than on $\mathrm{PP}_{31}$. On the $\mathrm{PP}_{31}$ sample, the largest deviation is visible after ethanol treatment, although this difference is smaller than on $\mathrm{OY}_{12}$ sample. The results correlate with the measured dE2000 values and show that the degradation on $\mathrm{OY}_{12}$ is higher on both media than on $\mathrm{PP}_{31}$ indicating poorer stability of that TC ink. 


\section{CONCLUSIONS}

After assessment of TC inks' resistance to rub and to selected liquid agents the following could be concluded.

Thermochromic UV inks showed good rub resistance as no rub was detected either by visual inspection or by spectrophotometric evaluation of colorimetric changes of the prints.

All tested TC prints showed low resistance to liquid chemical agents, especially to the ethanol, which as a strong solvent degraded the prints at the highest extent.

Higher bleeding of colorants was visually inspected from $\mathrm{PP}_{31}$ prints than form $\mathrm{OY}_{12}$ prints, while at the same time, spectrophotometric evaluation showed that prints made with $\mathrm{OY}_{12}$ inks had a lower resistance to all liquid agents in comparison to $\mathrm{PP}_{31}$ prints.

Highest colour differences were noticed when prints were in their "cold state", i.e. below their $\mathrm{T}_{\mathrm{A}}$ when thermochromic microcapsules were active.

The metallized label paper with a rougher surface was slightly more affected by the liquid agents than the one with smoother and radiant surface.

However, even though the prints were not able to completely withstand exposure to specific chemical agents which was demonstrated by their optical deterioration, the thermochromic effect was still present in them after the resistance tests were conducted.

\section{ACKNOWLEDGMENTS}

The authors are grateful for the financial support of the University of Zagreb (Financial support for research in 2020).

\section{REFERENCES}

[1] Bäckman, M.: "Feasibility study of thermochromic inks for the packaging industry", URL: https://lup.lub.lu.se/student-papers/search/publication/8905340 (last request: 2020-20-09), 2017.

[2] Bozhkova, T. T., Boeva, R., Spridonov, I., Sapkota, J., Nedelchev, Y. V., Kašiković, N., Dedijer, S., Pal, M.: "Improvement of physical-mechanical and optical properties of the packaging production through coating with aqueous polymer dispersions in accordance with the environmental protection requirements", Bulgarian Chemical Communications 49, 169-173, 2017.

[3] Brancher: "Fastness of inks: Chemical resistance", URL: http://www.brancher.com/-Resistance-auxagents-chimiques-.html?lang=en (last request: 2020-20-09), 2020.

[4] British Standards Institution, BS 3110(1959):1959 Methods for measuring the rub resistance of print, British Standards Institution, 1959.

[5] CIE: "Colorimetry, 3rd Edition", (CIE, Vienna, 2004.)

[6] Đurđević, S., Novaković, D., Vladić, G., Kašiković, N.: "The development of novel smart packaging labels and mobile application for protection, information and identification of product shelf life", Acta Graphica: Journal for Printing Science and Graphic Communications 26, 35-41, 2015.

[7] Homola, T. J.: "Color-changing inks", (McGraw-Hill Global Education Holdings, New York NY, 2008.). doi: 10.1036/1097-8542.YB080620

[8] International Organization for Standardization, ISO 2836:2004 Graphic Technology- Prints and printing inks- Assessments of resistance to various agents, International Organization for Standardization, 2004.

[9] Kulčar, R., Friskovec, M., Hauptman, N., Vesel, A., Klanjšek Gunde, M.: "Colorimetric properties of reversible thermochromic printing inks", Dyes and Pigments 86, 271-277, 2010. doi: 10.1016/j.dyepig.2010.01.014.

[10] Lam Po Tang, S., Stylios, G. K.: "An overview of smart technologies for clothing design and engineering", International Journal of Clothing Science and Technology 18, 108-128, 2006. doi: 10.1108/09556220610645766.

[11] Rožić, M., Vukoje, M., Kapović, D., Marošević, L.: "Solvents interactions with thermochromic print", Journal of Graphic Engineering and Design 8, 19-25, 2017. doi: 10.24867/JGED-2017-2-019.

[12] Rudolf, M., Plazonić, I., Petrić Maretić, K., Bates, I., Radić Seleš, V.: "Rub resistance of ink jet prints on laboratory substrates with wheat pulp", Printing\&Design 2020, (Fotosoft d.o.o.: Zagreb, Croatia, 2020) pages 126-131, 2020. 
[13] Seeboth, A., Lotzsch, D.: "Thermochromic and thermotropic materials", (CRC Press, Boca Raton FL, 2013.)

[14] Seeboth, A., Lotzsch, D.: "Thermochromic Phenomena in Polymers", (Smithers Rapra Technology Limited, Shropshire UK, 2008.)

[15] WRAP: "Using thermochromic inks to reduce household food waste", URL: http://www.wrap.org.uk/content/using-thermochromic-inks-reduce-household-food-waste-0 (last request: 2020-20-09), 2013.

[16] Zhou, W. H., He, B. H., Zhang, C. X., Han, Y.: "Analysis on Ink Layer Rub Resistance for Coated Paper Prints", Advanced Materials Research 380, 173-178, 2011. doi:

10.4028/www.scientific.net/AMR.380.173.

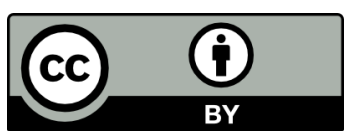

(C) 2020 Authors. Published by the University of Novi Sad, Faculty of Technical Sciences, Department of Graphic Engineering and Design. This article is an open access article distributed under the terms and conditions of the Creative Commons Attribution license 3.0 Serbia (http://creativecommons.org/licenses/by/3.0/rs/). 